began to develop on concrete and at the same time general problems in the newest branch of geometry, namely, topology, and on problems in algebra and analysis allied to it. New and important results in this field have been obtained by Pontyagin, P. Alexandrov, Kolmogorov and others.

The work of Russian mathematicians on analysis has many-sided characteristics. The qualitative theory of differential equations, which has numerous applications in astronomy, electricity, and so on, was dealt with before the Revolution in profound and original work by Lyapunov. This field has been taken up by N. Krylov, Bogolyubov and others. In the general theory of differential equations great progress was made before the Revolution, as is recorded in works of Steklov and Bernstein, and since by AlppoDanilevsky as well as by Petrovsky and Sobolev.

The application of methods of mathematical analysis to problems in mechanics, the theory of elasticity and hydromechanics has given very important results, as can be seen in the work of A. Krylov, Muskhalishvili and Lavrientyev, the last-named having propounded an important general theory concerned with the functions of a complex variable. More recently, a young Soviet scientific worker, A. Alexandrov, by the application of new methods, has produced important new geometrical results.

We cannot in this short article describe in any. thing like detail the many and varied achievements of Russian mathematics during the twenty-five years which have elapsed since the October Revolution. We propose to deal here only with some examples of pure mathematical investigation in algebra and geometry.

Algebra, which may be defined as the science of the abstract study of operations in addition and subtraction, can be carried out not only with numbers but also with vectors, oscillations in alternating current circuits, etc. Every combination the elements of which can be subjected to the operations of addition and subtraction is called a cumulative group. From this it can be seen that the study of cumulative groups is of extreme importance. The problem requiring solution was the explanation of the properties of continuous cumulative groups and a method of investigating them. This problem was first solved by the Russian scientific worker, L. S. Pontyagin, with the aid of a method which he originated and which has since been successfully applied to other branches of mathematics.

Geometry is the science of figures, and although many geometrical problems are subject to visual proof, their solution is nevertheless often very difficult. In 1916, the well-known mathematician, Weil, propounded a fundamental problem of convex surfaces which he himself could not solve in its entirety. In 1940, A. Alexandrov showed that Weil's problem could be solved as a special case, and developed a new general method in the theory of surface areas. The fundamental part of the results obtained by Alexandrov is his discovery of a theorem of polygons which, though simple to formulate, is far from simple to prove. This theorem makes it possible to build up a convex polygon from pieces of paper cut to certain shapes. It may seem strange that what is at first sight an interesting problem for a child should be the basis of profound geometrical theories. Even such a problem, however, offers the greatest difficulty in solution.

Apart from purely theoretical investigations, Russian mathematics pays considerable attention to the solution of problems of an immediately practical character. Among problems of this nature we may point to research in the theory of the aeroplane, particularly by Christianovich and Keldysh, to work on rational laws of gunfire, on the movement of a shell, on the calculation of dams by Senkov's system, and other similar problems. At the present moment, when the U.S.S.R. is carrying on a great struggle against Fascism, these problems are of primary importance and occupy many of our leading mathematicians. It would be interesting to deal with these problems in greater detail, were it not for the fact that their significance in the present War compels us to keep them secret.

From this very short sketch, it can be seen that Soviet mathematics has attained a very high level. There are in the Soviet Union a number of outstanding mathematicians working in all realms of mathematics, and there is our own original school of mathematics, which, although it omits various branches, makes it certain that further development of the science of mathematics lies ahead in the U.S.S.R.

\section{APPLICATIONS OF PHYSICS TO THE HEATING AND VENTILATION OF BUILDINGS*}

\author{
By A. F. DUFTON
}

Building Research Station, Watford

"The subjects of warming and ventilating, although in themselves simple, still deal with things and motions which are impalpable and invisible, and must be studied in their principles to be understood at all. Where the bodily eye can see nothing the mind's eye must note important processes. The peculiarity of the subject is proved by the fact of so many distinguished architects and engineers failing signally in undertakings to warm and ventilate."Neil Arnott.

Co early as 1784, James Watt used steam for 5 warming the room in which he commonly wrote, and his radiator, a box three and a half feet long, two and a half feet wide and one inch thick, was made of tin plates. The warming effect of this radiator, however, was less than he anticipated. The fact that Watt's expectations were not fulfilled serves as a reminder that engineering is, in a great measure, applied physics and that practical advances follow as and when progress is made in experimental physics. We now know that the radiator of 1784 did not emit sufficient heat because its surface was metallic, but it was not until 1801 that John Leslie discovered the nature and ascertained the properties of what is termed radiant heat.

Leslie found that the application of a coat of pigment to a metallic surface, instead of retarding the discharge of heat, nearly doubled it. He remarked that this fact, equally curious and important, was most contrary to the prevalent notions, and seemed not to have been hitherto observed. He showed that a tin canister, filled with hot water, cooled considerably faster after it was covered with flannel, and required the further addition of one or two

- From a lecture delivered before the Institute of Physics on November 17 . 
folds to make it cool at the same rate as before. "These remarkable facts," he declared, "bid defiance to the loose sort of philosophy, which, without requiring any exertion of mind, pretends to explain everything. They teach us the necessity of a sober scepticism and demonstrate the great utility of extending a critical inquiry into the various popular branches of physics."

Radiant heat is not a simple entity and we must distinguish, for example, between the radiation which we receive from the sun and the radiation from bodies at temperatures of, say, $0^{\circ}-100^{\circ} \mathrm{C}$. The wave-lengths of the radiation we receive from the sun are all less than $3.0 \mu$, and the wave-lengths of the radiation from a body at low temperatures are all greater than this.

It is interesting to recall that the infra-red rays were first discovered by Sir John Herschel in the course of a research into the properties of various kinds of coloured glass, undertaken with the view of the selection of suitable glass for use in viewing the sun through a telescope. He wished to discover which of the sun's rays furnished the greatest quantity of light without inconveniencing the eye with unnecessary heat. He observed that the heat became more and more considerable as a thermometer was moved towards the red rays in the solar spectrum, and found not only that the heat continued beyond the limit of the visible spectrum but also that it was there more intense than at any point within the spectrum.

The diathermanous power of a substance differs greatly with the heat from different sources. Glass is a notable example. It transmits freely the heat of the sun, but intercepts all the radiation from a source at a temperature below $100^{\circ} \mathrm{C}$. This property of glass enables us to trap the sun's heat in greenhouses and in dwellings. Glass transmits only six per cent of the heat emitted by a source at $400^{\circ} \mathrm{C}$.

It must be emphasized that, in general, the absorbing and reflecting powers of a surface for low-temperature radiant heat are different from the corresponding absorbing and reflecting powers for solar radiation. Ignorance of this has led to much confusion, since the property which bodies possess of absorbing, emitting and reflecting radiant heat meets with many applications. In that old text-book, Ganot's "Treatise on Physics", we are told that the outsides of stoves and hot-water apparatus ought to be black, to give free exit to the heat. This is quite erroneous; the colour of the paint makes no difference to the emission of heat from hot-water apparatus so long as the paint does not contain metallic flakes. Metallic paints, such as aluminium and bronze, vary somewhat, the average emissivity being about 50 per cent. An appreciably lower emissivity than this is said to be obtainable, presumably by taking care not to cover the metallic flakes with too much of the binding material. In the case of an ordinary cast-iron radiator, painting with aluminium paint is found to reduce the emission by about 10 per cent; the heat communicated directly to the air, which in the case of an ordinary radiator is greater than that emitted as radiation, is unaffected by the nature of the paint used.

When we remember for how long buildings in Great Britain have been heated by means of open fires, it is difficult to understand why so much reliance has been placed upon radiant heating and why the airwarming fireplace has never become popular. Such a fireplace heats a room by means of convection currents, the heat imparted to the air causing it to circulate throughout the room. Of the experimental physicists who have advocated such fireplaces the best known is probably Benjamin Franklin, who in 1745 described his newly invented "Pennsylvanian fireplace", by the use of which he reckoned to save no less than five sixths of the fuel required to heat a room. The Pennsylvanian fireplace was preceded by the fireplaces of M. Gauger, who in 1713 published a treatise on the subject which was translated into English by a physicist, Dr. Desaguliers, and published in 1716 under the title "The Mechanism of Fire made in Chimneys".

Some four years ago I contrived an air-warming fireplace in my own home and now obtain probably three times as much useful heat from the fuel burned as before. Even in midwinter, with snow lying, there is no difficulty in heating the room so that at a distance of $20 \mathrm{ft}$. from the fire the air tempera. ture is $70^{\circ} \mathrm{F}$. This fireplace is an adaptation of the "Cheminée de Nancy" of two centuries ago.

When heating is intermittent, as is frequently the case, it is important to reduce the heating-up period to a minimum, both for economy and con. venience. The problem is a physical one, and the basis for the necessary analysis was laid by Baron Fourier in his "Traité de Chaleur". It is now clear that for the most efficient use of intermittent heating the walls of a room should be lined with wood or other insulation of small thermal capacity; I believe that my experiments were the first to illustrate this. I measured the rate of warming of a room in my own home before and after I lined it with oak panelling. Without taking the furniture into account, only half the boundary surface of the room was changed by the panelling-the ceiling, window, floor and door were not affected-yet the change in the room was remarkable. The room is now warmer after half an hour than it used to be after an hour and a quarter's heating. From the practical point of view the important fact is not that one hour's heating now suffices instead of two, but that a fire may reasonably be lit half an hour before the room is wanted.

To turn now to the applications of physics to ventilation. In order to ventilate a room, an aero. motive force is necessary and the movement of air must be properly directed and controlled, especially if draughts are to be avoided. To illustrate how this may be done it is of interest to see how a physicist ventilated his house and, as an example, I cite Sir John Robison's house in Randolph Crescent, Edinburgh, and quote from the description given in 1839 by John Milne, an Edinburgh architect.

"The system of ventilation employed in this house appears to be as perfect as can be desired; as while the mass of air in the rooms and passages is constantly undergoing removal by the escape of vitiated air above, and the admission of large supplies of fresh air from below, no currents are perceived in the apartments, which, even when crowded with company and amply lighted, preserve a remarkable freshness of atmosphere. ... This is effected by means of cylindrical flues of earthenware, nine inches in diameter, built into the gables, in close proximity to the smoke flues of each room. The lower ends of these ventilating flues open into spaces between the ceilings of the respective rooms and the floors of those above them; and there is one or more of these exit air-flues in each room according to its size and use. The heated and vitiated vapours pass 
upwards through the ceilings by a continuous opening of about one inch and a half wide (behind one of the fillets of the cornice) all round the rooms, and having thus passed into the space between the ceiling and the floor immediately above, they ascend by the flues in the wall, and are discharged by them into the vacant space between the ceilings of the attics and the roof; from whence they find their way through the slates to the open air. The passage for the air through the cornice is not visible from the floor of any of the rooms.... The continued supply of fresh air to the lower part of the house, to replace that which goes off by the ventilators and by the chimneys, is brought in from the garden behind the house by a passage, the sectional area of which is eight superficial feet. The cold air admitted by this passage (or by a similar one from the front of the house) is made to pass over a stove. . . . The usual temperature of the air issuing from the stove is as low as $64^{\circ}$. The whole of this air is discharged into the well of the staircase, which forms a reservoir from which the rooms draw the quantity required to maintain the upward currents in the chimneys and in the ventilating flues. The air in the staircase finds its way into the apartments by masked passages, of four or five inches wide and four feet long, over the doors, and by openings left under each door of about one inch wide. The sectional areas of these passages are more than equal to the areas of the chimney and ventilating flues ... the quantity of escape is regulated by hand by means of throttlevalves at the mouth of each escape-flue. . . ."

It is interesting to note that, when asked in 1841 whether experience had suggested any alterations or improvements, Robison replied that, if the house were to be built again, the only difference he should make would be to form the air-passages still wider. To return to the present century, I can testify that one of the pleasantest living-room atmospheres which I have experienced was in a room provided with a ventilated cornice.

The temperature of a room with air and walls at different degrees is not easily specified. From the point of view of comfort, it is the rate at which heat is lost from the body which seems to be important, and the equivalent temperature of an environment is defined as that temperature of a uniform enclosure in which, in still air, a sizable black body would lose heat at the same rate as in the environment, the surface temperature of the body being one third of the way between the temperature of the enclosure and $100^{\circ} \mathrm{F}$. The scale of equivalent temperature, introduced by me in 1929 , is essentially a refinement of the sensation scale; it is measured by a eupa. th эoscope. When the instrument is placed in a room with air and walls at, say, $62^{\circ} \mathrm{F}$. and the air is still, it indicates $62^{\circ} \mathrm{F}$. If there is a draught of some $200 \mathrm{ft}$. per minute in the room, the instrument 'feels colder' and indicates $56^{\circ}$. The eupatheoscope is primarily an instrument for research.

Heating engineers are dependent to a great extent upon rule-of-thumb and in this age of progress are finding some difficulty in adapting standard practices and calculations to meet modern requirements. In the Heating Laboratory of the Building Research Station at Watford, we have a room with walls, ceiling and floor exposed to controlled conditions, and it is possible to study not only different methods of heating, the problems of intermittent heating and the influence of ventilation upon heating, but also those phases of building construction of interest to heating engineers. The temperature of the air in the enclosure is controlled by means of an extensive system of panel-warming and panel-cooling pipes in the walls, floor and ceiling. This enclosure is defined when the temperatures of the various surfaces are specified. The walls of the enclosure are heated or cooled by means of calcium-brine pumped through the embedded pipes, and the mean surface temperature of each wall is individually controlled to $0 \cdot 1^{\circ} \mathrm{F}$. by a copper resistance thermometer in conjunction with a sensitive relay system. Each wallsurface is tested once in every six minutes and the controls then automatically raise or lower the tem. perature of the brine by means of specially designed modulating valves.

The laboratory is designed for comparative work, and the most common form of heating in use at the present time-by cast-iron radiators-has been chosen as a standard of reference. This not only provides a convenient yardstick but also ensures that a substantial body of data is obtained about this important type of heating. The Institution of Heating and Ventilating Engineers has taken a great interest in the work at the Building Research Station, and there would have been no Heating Laboratory without the help of the Institution.

To many people the applications of physics which are of particular interest are those concerned with the development of automatic mechanisms. In this connexion I would like to invite attention to the contributions made by Dr. Neil Arnott, who was not only an eminent physician but also a competent experimental physicist. It is a hundred years ago now since Amott produced his 'thermometer stove', the temperature of which was directly controlled by a thermometer. He applied also the unequal expansion of two small bars, one of iron, the other of brass, to the control of the air supply for a stove; but his most elegant device was the 'balanced valve regulator' which he used to regulate stoves and boilers ; one of which served a small steam engine which worked a ventilating pump for months, night and day, having the attention only of a gardener, who put a supply of coal into the hopper morning and evening. With this regulator the air-flow is determined by the pressure exerted upon a plate. The weight placed on the steelyard is a measure of the quantity of air admitted to the fire and, with uniform combustion, a measure of the quantity of fuel consumed and of the heat produced.

I have mentioned a few of the physicists who have made practical contributions to the arts of heating and ventilation. Of all that has been achieved, however, in the field of heating research, there is nothing which quite compares with the work of Count Rumford. He was a great experimenter and devised methods of messurement and made determinations not only of the specific heats of various substances and the thermal conductivities of insulating materials but also of the calorific values of fuels. He strove to find out how to heat and light buildings economically and well. This was a subject which he had much at heart, and when he founded the Rumford Medal of the Royal Society, he wrote to the president :

"The objects which I had more particularly in view to encourage, are such practical improvements in the generation and management of heat and light as tend directly and powerfully to increase the enjoyments and comforts of life, especially in the lower and more numerous classes of society." 